\title{
Ethno-cultural and social problems of a students in a multicultural educational environment
}

\author{
Ekaterina Ivanova ${ }^{1}$, Julia Doncheva ${ }^{2}$ \\ 'Ekaterina Ivanova, PhD Student, University of Ruse 'Angel Kanchev', Bulgaria \\ ${ }^{2}$ Julia Doncheva, PhD, Assoc. Prof., University of Ruse 'Angel Kanchev', Bulgaria \\ ${ }^{3}$ University of Ruse, Bulgaria \\ Ekaterina Ivanova
}

\begin{abstract}
.
The publication traces some of the problems - social and educational, related to their ethnic and interethnic dimensions. Statistics are presented and their characteristics are analysed. Lately, the realities in the social and educational spheres have been one of the most discussed topics, it is working, but the results, as we wish them to be, and should be, have been extremely slow. Undoubtedly, the modern world is increasingly globalized - states, nations, ethnicities are in increasing economic, political, scientific and cultural interdependence. But paradoxically, with the tendency towards global homogenization, the old enmities and hatred of one ethnic group are being revived. It turns out that today, with globalization defining a fundamentally new way of forming relationships in the world associated with the disappearance of all borders, at the group level, there are processes of closure in which ethnic identification is crucial. This would be good if we are talking about preserving everyday life, culture, identity and uniqueness, but not when it comes to mistrust, misunderstanding, conflict, and even to xenophobic attitudes. In this regard, Bulgaria as part of Europe is no exception, migration waves are not avoiding us, they are part of our reality.
\end{abstract}

Keywords: discrimination; ethnic group; globalization; identification; migration;

\section{Introduction}

In the process of Bulgaria's accession to the European Union, one of the most important conditions for membership is respect for human rights, including ethnic minorities. Bulgaria has signed a number of international documents through which it has undertaken to work for their respect and implementation. One of the fundamental human rights is the right to education. The Convention for the Protection of Human Rights (Article 2) states that no one may be deprived of his right to education, and this right must be exercised without discrimination on any grounds whatsoever. [25] 


\section{Basic concepts}

2.1. Ethnicity. A reference to the Bulgarian Academy of Sciences Interpretative Bulgarian Dictionary on the term 'ethnos' we read as follows: 'The term 'ethnicity' is derived from the

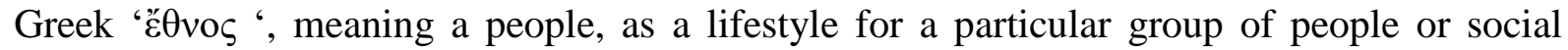
background. The term 'ethnos' is used to distinguish a group of people or a part of the people, or to preserve the cultural difference of a people from the rest'.

Today, ethnicity can be perceived as a community of people, historically distinctive in a given territory, communicates in a language understandable to all members, aware of its difference from other similar communities, and perceives its ethnonym (the name of the ethnic group). The high mobility (migration) of the population contributed to the fragmentation of many ethnic groups, which in turn facilitated the formation of new ethnic groups. Ethnic entities can be distinguished in this respect, such as:

- an ethno-social organism representing an ethnic group or part of it associated with a particular statehood;

- Ethnicity - represents the sum of all ethnic groups pertaining to a given ethnicity, regardless of their location '. [10]

Demographic situation in the country as of December 31, 2018, the population of Bulgaria is as follows: 7000039 people, which represents 1.4\% of the population of the European Union. Compared to 2017, the country's population decreased by 49,995 or $0.7 \%$. The males were $3395701(48.5 \%)$ and the females - $3604338(51.5 \%)$, or 1061 females per 1,000 males. The number of men predominates at the age of 53 years. With increasing age, the number and relative share of women in the general population of the country increases. [16] 


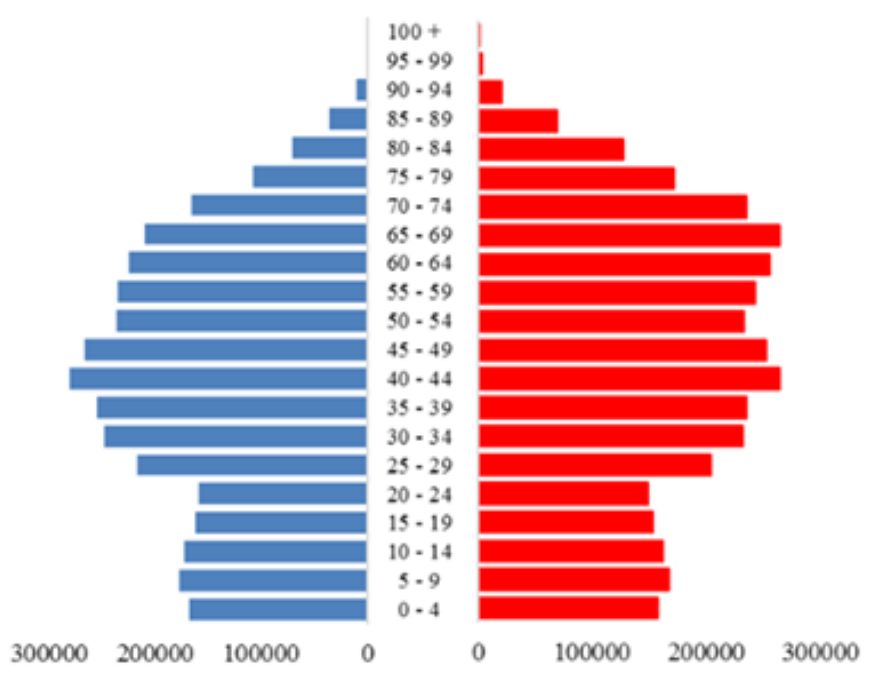

2.2. External migration. In 2018, 33225 people changed their current address from the country abroad, with $51.4 \%$ of them men. Every second emigrant (49.4\%) is $20-39$ years old. The youngest emigrants (under 20 years old) are 15.8\%, and those aged 60 and over $-9.2 \%$ of all emigrants. The most preferred destinations for emigrants are Germany (24.4\%), the United Kingdom (17.8\%) and Italy (7.5\%).

Persons who have changed their domicile from abroad in Bulgaria, or the flow of immigrants, include Bulgarian nationals who have returned to the country, as well as nationals of other countries who have obtained a residence permit or status in the country. In 2018, 29,559 persons changed their usual residence abroad in Bulgaria. The relative share of men is $49.3 \%$ and of women - 50.7\%. Among those who came to live in the country $35.5 \%$ are in the age group of 20-39 years, and $27.6 \%$ are aged $40-59$ years. The youngest immigrants (under 20 years) are $19.0 \%$ and the oldest (60 years and over) are $17.9 \%$. The highest is the share of immigrants from Turkey (29.9\%), the Russian Federation (11.0\%) and Germany $(7.2 \%)$.

2.3. The colourful rug of the Bulgarian ethnic map. A large percentage of people from different ethnic groups live in Bulgaria. Responding to the voluntary question on ethnicity (Table 1), they indicated the following: total number of persons answered 6680980 . Of these, 5664 624, Turks 588 318, Roma 325 343, others 49304 self-identified and did not self-identified 53 391. That is, $1.5 \%$ indicate 'other affiliation'. The major ethnic groups are Bulgarians, Turks and Roma. Who is behind this percentage and half and how colourful is the picture of the ethnic groups in Bulgaria? In particular, the information is as follows: Russians 15,595, Armenians 10,832, Vlachs 10,566, Macedonians 5,071, Karakachans 4,107, Greeks 3,408, Ukrainians 2,489, Arabs 2,328, Crimean Tatars 1 803, Jews 1 363, Romanians 1088 , Poles 825, Vietnamese 635, Gagauzes 540, Germans 436, Serbs 422, Circassians 367, Czechs 316, Albanians 278, French 195, Hungarians 169, Slovaks 161, Kurds 147, Africans 78, 
Slovenians 28, Bosnians 23. The small ethnic groups are found their Bulgaria, some of them have lived here for centuries. They are not shouting for rights, they are not socially included, probably because they have always felt like one of us.

Table 1. Ethnicity data

\begin{tabular}{|c|c|c|c|c|c|c|}
\hline \multirow{2}{*}{$\begin{array}{c}\text { District } \\
\text { Municipality } \\
\text { Populated } \\
\text { place }\end{array}$} & \multirow{2}{*}{$\begin{array}{l}\text { Persons who } \\
\text { answered the } \\
\text { voluntary } \\
\text { question on } \\
\text { ethnicity }\end{array}$} & \multicolumn{4}{|c|}{ Ethnic group } & \multirow[b]{2}{*}{$\begin{array}{c}\text { Not self- } \\
\text { determining }\end{array}$} \\
\hline & & Bulgarian & Turkish & Roma & Other & \\
\hline $\begin{array}{c}\text { TOTAL } \\
\text { FOR THE } \\
\text { COUNTRY }\end{array}$ & 6680980 & 5664624 & 588318 & 325343 & 49304 & 53391 \\
\hline
\end{tabular}

Of course, this diversity also raises its problems, which need to find an effective solution with a sustainable trend. On the topic, we find and base our research on scientific publications by the following Bulgarian and foreign authors: Kurkchiyska, V., Neminska, R., Radoslavova, L., Stefanova Evd., Stoyanova M., Topolska E., Alexandrache C., Al-Obaydi, L. H. \& all, Doncheva, J., Ivanova, E., Draganova, Ts. \& P. Daskalov, Engels-Kritidis, R.

Reality in the social and educational spheres is one of the most discussed topics, it is working, but the results, as we want and need to be, become very slow. $[1,2,4,5,6,7,14,18,19,21$, $24,27]$

\subsection{Adaptation practices for children of non-Bulgarian ethnic background.}

2.4.1. The role of parents. Undoubtedly, their role is fundamental and referential for a young child. In this regard, the publications of Dineva, V., Georgieva, E. \& M. Dushkova, Ivanova, A. \& G. Ivanova, provoked us to make a short survey among parents of young children. We sought their opinion on the issue of the attitude they are raising with their children through the following question: Do you have conversations with your children on the topic: 'Disabled children - children with disabilities?' $[3,8,11]$

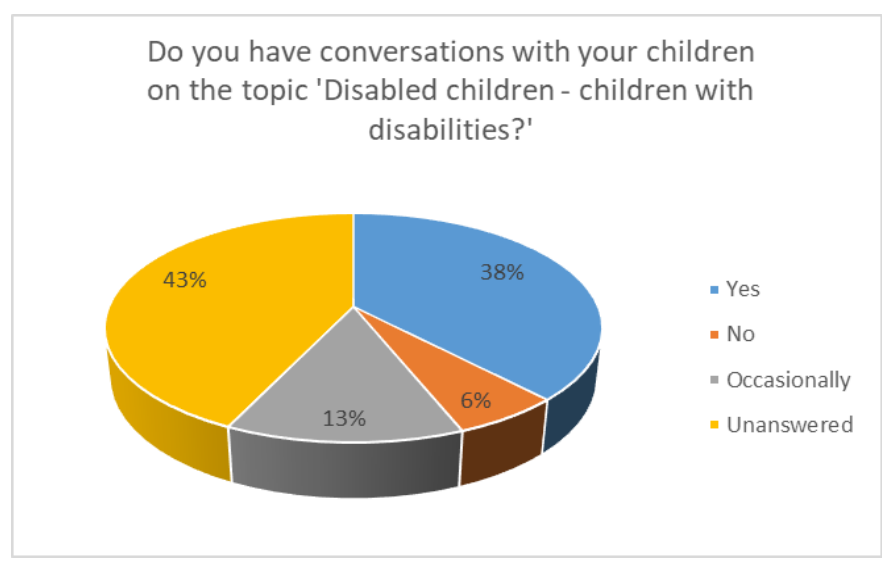

Figure 2. Respondents answers diagram 
From all the completed surveys it is clear that $43 \%$ (110) of the respondents did not answer the question, $38 \%$ (96) answered that they are talking to their children about disadvantaged children, $13 \%$ (34) of the participants say sometimes on the topic 'Disabled children children with disabilities' (Figure 2).

2.4.2. Communication in Bulgarian language. Their mother tongue is different from Bulgarian (Turkish, Armenian, Jewish, Roma, Vlach, Gagauz, Karakachan, etc.). Many of these families are living in extreme poverty, and this creates social exclusion. Often one of its manifestations is not attending school. There was a strong talk about the so-called. 'Demographic boom and enlightenment collapse'. Everywhere, efforts are being made to educate children in order to overcome the language barrier. First of all, the main difficulties come from the fact that they do not speak Bulgarian. They communicate with each other in Turkish or Roma. They are bilinguals, but not finished, they know their mother tongue completely and Bulgarian elementary. In kindergarten and first grade, teachers devote almost a whole school year to mastering the language, which hinders the learning process and thus, especially students, find themselves in the backward group. Learning another language is not an easy activity. In her monograph, exploring the phraseological semantics of the Bulgarian language as a reflection of our national mentality, E. Nedkova says: 'As inextricably linked to culture, language has the opportunity to reflect the common, universal components of human culture, and the peculiarity of a particular people, their mentality. On the other hand, the parameters of the human spiritual world are determined by the obligatory condition for man to be aware of himself as a part of humanity and at the same time to be perceived as representative of one or another human community. Thus, the anthropomorphic code contained in language is understood as a unity of individual and social approach.' [17] The longer a person is 'immersed' in the language environment - he listens, communicates verbally, etc., the faster and easier the language is acquired. Good practice is full-day schooling, where children are all day long among the Bulgarian-speaking peers.

2.4.3. Poor school facilities are another cause of learning problem, so-called semiliteracy. This is a lack of visual materials and, of course, affordable teaching equipment and supplies. Appropriately illustrated teaching material helps to understand, comprehend, assimilate and reinforce it. It should be remembered that pre-school children have a clear-cut thinking, i.e. to see everything, to accept with as many analysts as possible. The students in school have a clear-thinking, i.e. to see it, to put it into action. The new age in which the youngest generation is formed and grows also requires new approaches, ways, means, methods, techniques for the transfer, perception and comprehension of knowledge, skills, abilities (competences). In pedagogy, didactics and individual methodologies, there has long been talk of teacher-student interaction, not action (impact), learning by doing, by understanding. A supportive educational and information environment, an environment in which the role of information, digital, interactive and IT technologies in the education of students from the initial stage is an instrument, an aid in the hands of the modern Bulgarian teacher, not only as a unit, but also as part of the education system in Europe. [23, 29, 30]

2.4.4. Motivation for education. There is one driving force for the success of every human activity, for the achievement of certain aspirations, results, goals, including motives 
for its realization, namely motivation. High motivation is the impetus that drives a person to make a certain effort to achieve the desired goals or result, determined by a personally meaningful motive. In psychology, motivation refers to purposeful initial behavior, direction, intensity and persistence in action, a desire and willingness to achieve a claim. The motives are the internal motivation, the psychological mechanism for the effective involvement of personal regulators - the various settings that determine behavior. Motivation is the main driver in performing every activity. It should be emphasized that the formation of knowledge, skills and habits of adolescents is a long process, which requires not only patience and purposeful training, but also strong personal motivation for active involvement in the activity. Too high demands or lack thereof completely demotivate participants according to: Sotirov, Ch., Stoyanova, Ir., Ignatov, G. \& Petkova, Il., Ivanova, V. \& Mileva, E., Tsankova, M., B. Baycheva. The reluctance to study, to educate and create literacy creates serious difficulties for their equal participation in the whole life of Bulgarian society and raises a number of problems not only in school, not only in personal terms, but also in the production and various social spheres. [9, 12, 20, 25, 28]

2.4.5. The poor financial and material situation of many Roma and Turkish families is a fact, which is why many students are not able to attend school, especially during the winter. Their parents have been struggling to buy shoes and clothing this season, which is a problem, especially for those in large families. The social benefits they receive are

extremely inadequate. The bad thing is that there are already long-term unemployed parents who not only have no opportunity but also have no desire to look for a job, which in turn is a model of behavior. In today's situation, in the context of qualitative changes in society, culture and in the personal system, as well as the related changes, the negative effects of stereotypes in communication between people are amplified. Relationships in modern society are so situational and modelled that in the formation and upbringing of children, an increasing share of the street, the friendship circle, the virtual space, at the expense of the increasingly limited perimeter of influence of parents and family due to poor communication.

2.4.6. Key competences. The policy in the field of education is determined in accordance with the requirements of the European Union for Bulgaria's membership in it, the Government Program for Integration, Economic Growth and Social Responsibility, the National Program for School Education and Pre-school Education and Training, the National Strategy for the Introduction of Information and Communication Technologies, National Research Strategies, Education and Training 2020 Work Program in the context of the Lisbon Strategy. Education, according to Jacques Delors, should be organized around 'four fundamental types of training that, over the course of everyone's life, serve as pillars of knowledge, also reflected in the motto of the Concept for the Law of Pre-primary and Secondary Education:

- learning to know what it means to master the ability to understand;

- to learn to do so that we can be constructive in all conditions;

- to learn to live together so that we can participate and cooperate with other people in all human activities;

- learning to be, which means moving forward. [15] 


\section{The World Conference on Research in} TEACHING and EDUCATION

The so-called Key Competencies represent a transferable, multifunctional package of knowledge, skills and attitudes that all people need in terms of personal realization and development, inclusion and employment. They should be developed from the end of compulsory school education or training, and should act as a basis for further learning as part of lifelong learning.

2.4.7. Remigrants. Very briefly, we will only pay attention to another problem, almost not commented on in the pedagogical circles, related to the topic under discussion, namely: useful information is available on the issues of inclusion and integration of children from other ethnicities and cultures in the Bulgarian model, but how is this the case with the Bulgarians who were born and resided outside Bulgaria and returned to their homeland again, the so-called remigrants? What did the little Bulgarian women miss during this time? How will they integrate into the new environment, do they have a national value system, do they know Bulgarian culture, do they have the confidence of Bulgarians, are they attached to their home country? These issues, this topic, will be addressed in a subsequent, separate publication, due to its broad scope, dictated by the need for a thorough analysis.

\section{Conclusion}

For the younger generation, lifestyle is vital to their growth, development and prosperity. In the new highly technological, computerized, digital (age), healthy lifestyles mean a set,

apart from (not just) healthy eating, but mostly through physical activity, shaped, validated and realized as a physical culture, a model of life, a behavior, emotional satisfaction, overcoming stress with the effectiveness and resilience of the forms and methods of these effects. [21]

Communication skills are directly related to meeting needs and are tools for understanding, problem-solving and support. Disturbed relationships, regardless of the factors that cause them, generally impede the normal formation of the child's personality. As a result, the child's ability to adapt is reduced, the risk of mental disorders sharply increases, the degree of unmanageability, uncontrollability, and sometimes the inadequacy of its behavioral manifestations increases.

Interaction between different ethnicities involves knowledge of one another, that is, intercultural topics. [13] The better the cognitive knowledge is, the better the social. A 'one in diversity' motto that represents Europe as a continent with many different traditions and languages, but also with common values. Bulgaria, as part of Europe, must be in tune with European policies on ethnic cohesion and interaction. Interculturalism deepens in the interactions and communication between different ethnically defined cultures. Typical of her emphasis is sharing, sharing between cultures, mutual penetration and enrichment with one another.

Positive emotional attitudes towards members of a particular sociocultural and ethnic community, their own position in it and the manifestations of children's freedom to choose opportunities according to their own needs and interests are guarantees for the adaptation and integration of the child in the social environment as part of a group and at the same time as a person. autonomous subject. 
Coexistence between the compact majority and ethnic minorities is one aspect of social development and a hallmark of the democratic development of society.

\section{Acknowledgment}

The study was supported by contract of University of Ruse 'Angel Kanchev', № BG05M2OP001- 2.009-0011-C01,'Support for the development of human resources for research and innovation at the University of Ruse 'Angel Kanchev'. The project is funded with support from the Operational Program 'Science and Education for Smart Growth 2014 2020' financed by the European Social Fund of the European Union.

\section{References}

[1] Alexandrache C. (2017), Role - Play and the Development of Intercultural Competences in the Academic Education Process, B: 9th LUMEN International Scientific Conference Communicative Action \& Transdisciplinary in the Ethical Society | CATES 2017, 24-25 November 2017, Targovishte, Romania, Communicative Action \& Transdisciplinary in the Ethical Society.

[2] Al-Obaydi, L. H. \& Al-Bahadli, K. Khansaa. Hassan Al-Bahadli (2018), Examining the Effects of Using Social Strategies on EFL College Students attitudes towards using Self_ Peer Assessment. International Journal of Management and Applied Science, Volume - 4, Issue - 6, Jun-2018, Available: https://www.researchgate.net/publication/327222544

[3] Dineva, V. (2018), Family Therapy, Ruse.

[4] Doncheva J. \& E. Ivanova (2018), Contemporary Challenges and Expectations of Inclusive Education in the Republic of Bulgaria in: VI International Scientific Conference 'Contemporary Education - Condition, Challenges and Perspectives', 'Goce Delchev' University - Shtip, Macedonia, Faculty of educational sciences.

[5] Doncheva, J. (2017). Principles of training in line with the new thinking and action. // SEA - Conf., 3 International Conference, Naval Academy Romania, Constanta, No 3.

[6] Draganova, Ts. \& P. Daskalov (2009), Building educational software tools in an environment MATLAB, International Scientific Conference 'The European Dimensions of Education and Science', TK- Iambol, Vol. 7:2.

[7] Engels-Kritidis, R. (2015). Inclusiveness for all: the importance of individualization and differentiation for achieving educational progress in children in kindergarten. Journal of Preschool and Elementary School Education, number 2/2015(8), Special issue on topic: 'Inclusiveness in preschool and elementary school education as a space for diversity '.

[8] Georgieva, E. \& M. Dushkova (2018). Axological Aspects in the Tale Medenata Pita by Konstantin Konstantinov. In: Zeszyty Cyrylo-Metodiaǹskie. Vol 7 (2018).

[9] Ignatov, G. \& Petkova, Il. (2019). Academic motivation of students in physical education and sport at Sofia University 'St. Kliment Ohridski'. In Trakia Journal of Sciences, Vol. 17, Suppl. 1, Trakia University, Available: http://www.uni-sz.bg

[10] Interpretative Dictionary in Bulgarian, BAS, Available: http://talkoven.onlinerechnik.com/ 
[11] Ivanova, A. \& G. Ivanova (2009). Net-generation learning style - A challenge for higher education. Proceedings of the 2009 International Conference on Computer Systems and Technologies and Workshop for PhD Students in Computing, CompSysTech 2009, Rousse, Bulgaria, June 18-19.

[12] Ivanova, V. \& Mileva, E. (2019). Teachers' satisfaction with their professional activities in physical education and sport. In P. Hájek, \& O. Vít (Ed.), CBU International Conference Proceedings. 7.

[13] Koleva, I. (1996), Socialization, reflection, situations. A Practical Guide for the Child Teacher, Sofia.

[14] Kurkchiyska, V. (2017), Inclusive education - a challenge for the primary teacher, Shumen.

[15] Ministry of Education and Science, Available: http://www.mon.bg

[16] National Statistical Institute, Available: http://www.nsi.bg/census2011/pagebg2.php

[17] Nedkova, E. (2011), Phraseologies as signs in the language of culture, Ruse.

[18] Neminska, R. (2018), Contemporary Aspects of Civic Education, Stara Zagora.

[19] Radoslavova L. (2018), Strategies for Overcoming Educational Inequality, In: Proceedings of the Annual Scientific Conference of the National Military Academy 'Vasil Levski', Veliko Tarnovo

[20] Sotirov, Ch. (2017), Health Education of Preschool Children, In: Educational Technology, Shumen.

[21] Stefanova, Evd. (2017 b), Digital competence of elementary school students in human-society and human-nature interactions. In: International journal Skopje, 16 (1).

[22] Stefanova, Evd. (2017 a), Civic and social competence in the perception of the world at primary school age. Pedagogical News, Issue 1.

[23] Stoyanov, Y. (2014). Using WordPress, Environment for Distance Learning. Conference: Annual University Scientific Conference, Vasil Levski National Academy of Sciences, At: Veliko Tarnovo, Bulgaria.

[24] Stoyanova M. (2011), Models for inclusive game training for children and parents. Annual scientific and methodological journal 'Innovations in training and cognitive development', Issue no. 2, Burgas.

[25] Stoyanova, Ir. (2019), Innovative technologies and their place in education. In: Proceedings of the Istanbul - Kusadasi - Izmir Travel Seminar, Innovations in Education, Shumen University 'Konstantin Preslavski'.

[26] The European Convention on Human Rights, Available: https://www.echr.coe.int/Documents/Convention_BUL.pdf

[27] Topolska E. (2019) Content and diagnostic aspects of children's teacher's communicative competence. In: Pedagogical Communication: Traditional and Digital. Second International Scientific Conference. 
[28] Tsankova, M., B. Baycheva (2017) Professionally practical preparation of studentsfuture primary teachers. In: KNOWLEDGE - International Journal, Volume 19.1. September, 2017.

[29] Tzokov G. (2018) About the Financing of the Bulgarian School. In: Strategies for policy in science and education, Bulgarian Educational Journal, Volume 26, Number 1, Sofia.

[30] Vojnohovska, V. (2012), Information Technology and Multimedia as Factors for Increasing Student Motivation and Effectiveness of the Learning Process, Ruse. 